\title{
A Conceptual Discourse on Consumer's Preference of Brandy
}

\author{
Raj Maharjan ${ }^{1,2}$
}

1 Quest International College, Pokhara University, Nepal

2 Sales Executive, Gorkha Brewery, Kathmandu, Nepal, maharjanraj86@gmail.com
Received:25 Sept, 2019

Revised: $25 \mathrm{Nov}, 2019$

Accepted: 12 Dec, 2019

Published: $28 \mathrm{Jan}, 202 \mathrm{O}$

How to cite this paper: Maharjan, $R$. (2019). A conceptual discourse on consumer's preference of brandy. Quest Journal of Management and Social Sciences, 1(2), 296-307.

Copyright (C) 2019 by authors and Quest Journal of Management and Social Sciences

This work is licensed under a Creative Commons Attribution-NonCommercial-NoDerivatives 4.0 International License.

https://creativecommons.org/licenses/ by-nc-nd/4.0/

\begin{abstract}
Background: Liquor industry is growing to become a global giant by empowering its competitiveness. Nowadays, alcohol has been accepted and welcomed as a normal part of everyday life with innovatively embedded alcohol development and promotion. Alcohol products consist of a range of offerings including Gin, wine, vodka and Scotch, among which brandy has been gaining higher importance.
\end{abstract}

Objectives: This paper explores the consumers' preferences for brandy, their knowledge on brandy and also the factors determining the consumer choice on consumption of brandy. This study aims to contribute to the brandy consumer behavior-responsive managerial implications, especially in hospitality industry by identifying the attributes that are perceived important for the marketing of brandy to a large segment of dynamic market.

Methods: The academic discourse on this paper includes exploration of multiple dimensions related to the study of consumer behavior. Theories concerning consumer preferences, with specific focus on Reasoned Action Theory, Engel Kollat Blackwell Model, Hybrid Choice Model, Hedonic Price Model, Consumer Perception Factor Model and Conjoint Analysis are reviewed. The study on brandy, along with the differences from other alcoholic beverages, has also been included.

Findings: Brandy represents a wide category and the bases of differences among types of brandy are studied along with the review of brandy products available worldwide. This study highlights brandy consumption practices in the world, benefits of brandy consumption and people's perception towards brandy among other alcoholic beverages.

Conclusions: Alcohol is the fastest growing industry and requires consumer preference for the promotions and penetration of the product into the market, and for developing the product and improving it further.

Keywords: alcohol, liquor, brandy, taste, preference, consumers' behavior

Paper Type: Review Paper

JEL Classification: L11, M31 


\section{Introduction}

The alcoholic beverage consumption is increasingly becoming common among the global populace as a tool of socialization, especially among young people (Alcoholic Beverages Market Research Report, 2019). Alcohol beverages are a part of improving social gatherings as well as the culture of eating and people had started consuming alcohol since the ancient time in various forms like beer, wine and spirit. Alcohol beverages have, long since, become an integral part of many cultures (Nayak \& Prabhu, 2013; Harrison, 1971). In 2017, the global alcohol beverage market consisted of $\$ 1324.1$ billion and was expected to reach $\$ 1,684$ billion by 2025, with the compounding annual growth rate of $2.0 \%$ from 2018 to 2025 . This made premium alcoholic beverages market one of the primary drivers for the liquor market (Prasanna, 2017). At present, the alcohol industry has become the most trending industry in the world due to the increasing demand for alcoholic beverages in economically emerging countries like India, China, Indonesia and Singapore (Business Wire, 2018). While comparing preferences to alcoholic beverage types, only minor changes have been globally observed. Approximately, $44.8 \%$ of the total recorded alcohol is consumed in the form of spirits, followed by beer $34.3 \%$ and wine only by $11.7 \%$ (World Health Organization, 2018). In 2018, the consumption of gin grew by $8.3 \%$ more compared to 2017 , selling more than 72 million nine-liter-cases globally. Gin was followed by whisky, with $7 \%$ increase from the previous year, with 581 million nine liter cases. Mixed drinks (cocktail, long drinks and flavored alcoholic beverages) consumption increased by $5 \%$. There was a decrease in vodka consumption by $-2.6 \%$, with a forecast to lose 4.5 million cases by 2023 . Beer sales decreased by $2.2 \%$ and the global retail wine sell decreased by $1.6 \%$ in volume with the projected value of US $\$ 224.5$ billion by 2023, up from US $\$ 215.8$ billion in 2018 (Davitt, 2019).

According to Louw, (2014) brandy is a distilled spirit made from fermented grapes, with a volatile composition consisting of compounds, from various chemical families: alcohols, carboxylic acids and their esters, aromatic compounds, furan derivatives, ketones and terpenes with at least $36 \%$ of alcohol volume. The similarity between the brandy and other liquors is the alcohol content, which is between $45 \%-50 \%$. The difference then is in the raw materials used in the production process of brandy and other liquors. Brandies are prepared through the fermentation of fruits. They provide benefits like boosting immune system, boosting heart health, soothing sore throats. They are used as a sleeping aid, have anti-aging properties and help in controlling weight (Stanz, 2018; Stearns, 2018)

According to Desoublin, brandy is categorized as premium liquor, signifying the social status. Rathod et al. (2018) mentioned that Hungarians perceive brandy as a healthy drink and serve it at the end of a meal, a drink to be consumed as the first thing in the morning, during the middle of the night, or women prior to a rubbish- scavenging trip but considered as inappropriate to serve it outside these specific situations. The research article by Wiki, (n.d) explains that the consumers' brandy selections are dependent on the fruits used, age time, aroma, oak barrels used and finally the taste. It has also revealed that the differentiating character of brandy from other working alcoholic beverage is its taste and flavor to mouth. Marketing has become a vital to any business and is the key process of researching, promoting, and selling products 
to the target market. Besides having the best marketing strategy, the demand for the alcoholic beverage may decrease due to the state tax like health tax and excise duty tax imposed on alcoholic beverages. There is a positive function of alcohol consumption on inflation and negative relation with unemployment and death (Kitchin, 1981). Therefore, alcoholic beverages must promote the product to create demand, even at the period of price increment.

Every product has its own intrinsic value, required to be promoted through extrinsic factors like brand name, license and trademark. Passovaara (2012) argued that the marketing strategies must be developed for improving the image of and for consolidating the product in the consumers' mind. Generally, the marketing strategies developed emphasize on promoting the intrinsic properties of the product by means of extrinsic attributes like brand name, trademark and labels. Pentz and Gerber (2013) are concerned with the brand and image building of the product rather than sensory marketing like taste, smell and sound. The most popular marketing strategies among the beverages are the visual attractions, connecting with other organizations, and linking to cultures and events. At the present state, social media have provided a proper platform to alcohol beverage industries for marketing their products. The study of Niland et al. (2016) concludes that the online alcohol marketing is facilitating among close friends endorsing invitations to drink, taking up the content for Facebook friendship fun and such activities are often objected to as intrusions into online friendship activities. Marketing of alcohol beverages through social media encourages networked peer groups to consume alcohol exploiting the new forms of promotion strategies. Therefore, promoting alcohol consumption through the aspects of health benefits, the application of marketing tools and techniques can increase the level of awareness and knowledge of brandy among people. At present, the advanced forms of social media and technology have made a trend of social media marketing. Not only the brandy, the various alcoholic beverage products can be promoted through social media marketing like Facebook and YouTube at local level as well. The marketing patterns can be developed with strong affiliations to popular sports and entertainment companies who have high sponsorship and high advertisement budgets.

This study aims at contributing to the brandy consumer behavior-responsive managerial implications, especially in hospitality industry by identifying the attributes that are perceived important for the marketing of brandy to a large segment of dynamic market.

Further, the remaining of the paper is organized into four sections. Section 2 reviews the relevant literature, followed by materials and methods used in Section 3. Section 4 discusses the key issues and, finally, Section 5 draws conclusions based on the discussions in the previous sections.

\section{Review of Literature}

\section{Categorization of alcoholic drinks}

Liquor industry is growing to become a global giant and is becoming more competitive. Nowadays alcohol is seen as a normal part of everyday life and today alcohol products are much more salient. Alcoholic beverages can be understood as portable liquid containing $1 \%$ to $75 \%$ AVB (alcohol by volume). of liquor. They are produced through the introduction of yeast for 
fermentation and through various procedures like fermented beverages, distilled beverages, fortified beverages. They can be classified into wine, beer, whisky, brandy, aperitif, liqueur, spirits and sake, depending upon the abbreviation of alcohol contained ("Food \& Beverage", n.d.: para 1). Units like weight, meter and liter have been developed for making the measurement scientific and specific. Similarly, the measurement unit developed for the alcohol is ABV Alcohol is expressed in milliliters of alcohol per 100 milliliters of beverage, or in short as \% ABV (percent of alcohol by volume), Vol \% or \% vol (volume percent), proof (\% abv x 2) (“Alcoholic beverages", n.d.: Amount of alcoholic beverages, par 1). Alcoholic beverages are classified on the basis of their raw materials and processes, where liquid purifications are made through distillation for removing the diluted components for the purpose of increasing the proportion of the alcohol content. According to Mandara (2018), the increase in ABV signifies higher alcohol content in the product and can be classified as wine, brandy, gin, rum, vodka, tequilas and whisky. Wines are produced through the fermentation of grapes and aging process. They contain below $9 \% \mathrm{ABV}$ to above $16 \% \mathrm{ABV}$ and can be classified into red, white, rose, sparkling and fortified. Spirits are distilled alcohol beverages, containing high amount of alcohol from about $20 \%$ to $65 \%$ of ABV. Brandy is an alcoholic drink produced by distilling wine and contains around $35-60 \%$ of $\mathrm{ABV}$, which can be classified into grape brandy, fruit brandy and pomace brandy. Gin is produced by distilling juniper berries and contains $37-40 \%$ ABV. Rum is an alcoholic beverage produced from sugarcane juice through fermentation and distillation process. They are aged for around 30 years or more and contain $40-50 \%$ of ABV. Vodka is an alcoholic beverage produced through fermentation and distillation of potatoes and grains like wheat, rye, corn, fruits or sugar. They contain purified ethanol and water and contain 35-50\% of ABV. Tequilas are produced from plants called agave and contain $40-50 \%$ of $\mathrm{ABV}$ with varieties of color depending on aging processes, methods and time durations. Whisky is the alcoholic beverage produced through the wheat, barley, rye and corn and contain around 40-53.3 \% of ABV. It can be classified into various types like Bourbon whiskey, Single Malt, Tennessee Whiskey, Rye Whiskey and Cask Strength Whiskey.

\section{Categorization of brandy with the brands of brandy available worldwide}

Brandy is a spirit made through the fermentation and distillation offruits such as apples, plums, pears and grapes. It involves a wide range of portable spirits, made mostly from grape wines, fruit juice, fruit pulp or skin of grapes with a volatile composition consisting of compounds from various chemical families: alcohols, carboxylic acids and their esters, aromatic compounds, furan derivatives, ketones and terpenes with at least $36 \%$ of alcohol volume (Louw, 2014; Bougas, 2014). The only difference between liquor and brandy is the raw materials used and the fermentation process applied in brandy. Jacki (2019) classified brandy into nine types depending on the raw materials used, procedure and its aging. They are Cognac, Armagnac, Calvados, Spanish, Brandy de Jerez, Obstler, Pisco, Armenian, South African, Cypriot and Pomace.

Cognac is the most famous types of brandy in the world produced from grapes grown in 79,000 hectare AOC region of South West France in the copper pot stills. Armagnac brandy is produced through a single distillation process using grapes as the raw material and it is 
a product from South West France. Calvados is an apple spirit produced through distillation and fermentation of flavored apple and aged in oak barrels. Brandy de Jerez is produced by aging it in the casks that have held sherry in the past. They use the solar heat for aging. Similarly, Obstler brandy is a fruit brandy produced in Alpine regions of Austria and Switzerland and becomes a clear liquid through double distillation. Pisco is a brandy produced through the distillation of sweet grapes with high-sugar content and it is aged for the minimum period of three months in a container like glass, stainless steel or traditional clay pitchers. Armenian brandy is produced through double distilling procedure of grapes and is similar to Cognac brandy. South African brandy is produced from both pot distillation as well as column distillation. It contains at least 30\% of pot distilled brandy. Cypriot brandy is produced through double distilling process in copper pot stills and aging it in Limousin oak barrels. Pomace brandy is produced using the solid remains of crushed grapes or fruits and is also popularly named Grappa. Therefore, brandies are classified on the basis of taste, color, aroma and the varieties of fruits grown at different region that are used in fermentation. There are varieties of brandies in market sold globally with their own individual style, aroma and flavor. But among the brandies, cognac is considered as the liquor of gods, symbolizing a French luxury, the best brandy money can buy. Some of the global brands of brandy sold worldwide are Emperador Brandy, Hennessy Cognac, Dreher Brandy, Old Admiral Brandy, Martell Cognac, Remy Martin Cognac and MCDowell's No 1 Brandy.

\section{Theories on consumer preference}

Consumer preference is the attitude of an individual towards a set of objects that provide the greatest anticipated utility to the consumer. Various theories have been developed on consumer preferences, explaining the theoretical dimension of the study. The major theories that are considered during the study on consumer preference are Theory of Reasoned Action, Engel Kollat Blackwell Model, Hybrid Choice Model, Hedonic Price Model, Consumer Perception Factor Model and Conjoint Analysis. All these theories discuss various factors, stimulus and determinants that guide a person in making the selection of the product. Theory of reasoned action on consumer preference, developed by Fishbein and Ajzen, explains that the most proximal cause of behavior is the behavioral intention determined by attitude and subjective norm. Therefore, this theory states that attitude on behavior is influenced by various situations. As Paudel et al. (2018) and Paudel and Devkota (2018) stated that people, culture, perception and behavior are equally emphasized for purchasing goods. The Engel Kollat Blackwell Model, developed by J.F. Engel, D.T. Kollat and R.D. Blackwell (1968), states that the values, lifestyles, personalities and cultures influence the consumer decision making process. Kim et al. (2014) stated that hybrid choice model is the expanded form of discrete choice model framework and is used for identifying various factors that are considered by people while making decision for purchase among the finite set of alternatives. According to Khorshiddoust (2013), the Hedonic Price Method is used as the preference method of valuation and uses surrogate markets for placing a value on environmental quality. While evaluating a product, both intrinsic and extrinsic factors are considered. Therefore, it is a statistical model adopted for property price appraisal and to identify factors or influences on the price 
of goods through the intrinsic characteristics and external factors. The Consumer Perception Factor Model developed in Jaafar et al. (2012) affirmed that the consumers' perception is the combination of consumer's attitude, intrinsic and extrinsic factors. It states that the consumers' purchase intention is derived by 'the way of thinking', due to which once the person gets a negative experience with the product, he/she will always have negative bias in the future purchases. Likewise, they can have positive impact only when the quality is matched by the price. Dubas and Strong (1993) mentioned that conjoint analysis can be used for determining preferences on the basis of the bundles of attributes rather than individual attributes. This technique is based on the assumption that people evaluate objects, product or service in total and make trade-offs among the various levels in determining preferences.

\section{Empirical studies}

Empirical review examines the research based on the observed and the measured phenomena for deriving knowledge from actual experience rather than the theory of beliefs. There have been various studies conducted on the consumer preferences and this study covers the topic of consumer preference for brandy.

Table 1: Empirical Review

\begin{tabular}{|c|c|c|c|c|}
\hline Authors & Method & Countries & Findings & Recommendation \\
\hline Guris (2006) & $\begin{array}{l}\text { Multi nominal } \\
\text { logit model. }\end{array}$ & $\begin{array}{l}\text { Marmara } \\
\text { region in } \\
\text { Turekey }\end{array}$ & $\begin{array}{l}\text { Brand preference } \\
\text { depends on brand } \\
\text { name, occupation, } \\
\text { gender and income }\end{array}$ & $\begin{array}{l}\text { Promotion of product on the } \\
\text { basis of occupation and income } \\
\text { and prestige }\end{array}$ \\
\hline $\begin{array}{l}\text { Pettigrew \& } \\
\text { Charters (2009) }\end{array}$ & $\begin{array}{l}\text { Ethnographic } \\
\text { approach }\end{array}$ & Hong Kong & $\begin{array}{l}\text { Products symbolism } \\
\text { important than taste } \\
\text { considerations }\end{array}$ & $\begin{array}{l}\text { Reflect the culture and symbol } \\
\text { on packaging of product }\end{array}$ \\
\hline Dey et al. (2013) & $\begin{array}{l}\text { Logistic } \\
\text { regression }\end{array}$ & Switzerland & $\begin{array}{l}\text { Higher possibility of } \\
\text { using alcohol with the } \\
\text { risky drinking behavior. }\end{array}$ & $\begin{array}{l}\text { Regulations for controlling } \\
\text { the large quantities alcohol } \\
\text { consumption especially of } \\
\text { cheaper spirits }\end{array}$ \\
\hline $\begin{array}{l}\text { Mkosi et al. } \\
\text { (2014) }\end{array}$ & $\begin{array}{l}\text { Structural } \\
\text { model }\end{array}$ & South Africa & $\begin{array}{l}\text { People consume alcohol } \\
\text { during leisure time }\end{array}$ & $\begin{array}{l}\text { Beverage industry and the } \\
\text { health institutions work together } \\
\text { to reduce the alcohol related } \\
\text { problems }\end{array}$ \\
\hline $\begin{array}{l}\text { Sancho \& Aldas } \\
\text { (2016) }\end{array}$ & $\begin{array}{l}\text { Self- } \\
\text { administered } \\
\text { questionnaire }\end{array}$ & Spain & $\begin{array}{l}\text { Peers, family and } \\
\text { advertisement influence } \\
\text { youth and adolescents } \\
\text { for alcohol consumption }\end{array}$ & $\begin{array}{l}\text { Strict regulations on the } \\
\text { advertisement of alcoholic } \\
\text { beverages for reducing the youth } \\
\text { towards alcohol consumption. }\end{array}$ \\
\hline $\begin{array}{l}\text { Mehta \& Bhanja } \\
\text { (2017) }\end{array}$ & $\begin{array}{l}\text { In-depth } \\
\text { interviews }\end{array}$ & Singapore & $\begin{array}{l}\text { Price, brand, taste, } \\
\text { origin and type of wine } \\
\text { are considered by young } \\
\text { Indian consumers }\end{array}$ & $\begin{array}{l}\text { Apply marketing strategy by } \\
\text { grouping people with similar } \\
\text { preferences }\end{array}$ \\
\hline $\begin{array}{l}\text { Sawagvudcharee } \\
\text { et al. (2018) }\end{array}$ & $\begin{array}{l}\text { Regression } \\
\text { analysis }\end{array}$ & Nepal & $\begin{array}{l}\text { Beer brand is positive } \\
\text { with the brand loyalty } \\
\text { but does not have } \\
\text { significant casual } \\
\text { relation. }\end{array}$ & $\begin{array}{l}\text { Focus on the pricing strategy, } \\
\text { revenue management strategies } \\
\text { and promotional strategy to } \\
\text { develop the consumer purchase } \\
\text { decision }\end{array}$ \\
\hline
\end{tabular}


Above studies reveal the key findings of different empirical studies like the product symbolism being greater than the taste consideration. The other study made on Indian young consumers on winefound that the young consumer focus on the price, retail price, taste and brand while purchasing alcohol beverages. There is also the case of the difference between the consumers' stated willingness to pay and the actual price they pay in the case of the environmental products. It has also been highlighted that the product success depends on the advertisement and promotion, along with the intrinsic factors of the product. The nation can control the alcohol consumption through increasing the tax on alcohol beverages and people prefer restaurants that provide "bring your own bottle" facility. The study also reveals that the dependency of brand preference on brand name, occupation, gender income and in most of the cases people drink alcohol in leisure time.

\section{Conceptual Framework}

It is assumed that the moderate alcohol consumption has positive effects on health and people prefer distilled alcohol from fruits rather than other beverages. The study made on the impact of alcohol consumption by Lorimier (2000) concluded that men who consume 1 to 4 drinks per day and women who drink 1 to 2 drinks per day have lower risks of diseases compared to nondrinkers or to those who consume an excess of 4 drinks. Alcohol arguably is the oldest social beverage and has the power to change behaviors positively and negatively, but the reasons and effects for drinking vary widely from culture to culture. Pettigrew and Charters (2006) have revealed that the consumption of the locally or state produced wine depends on the demographic and attitude of the people.

\section{Figure 1: Conceptual Framework}

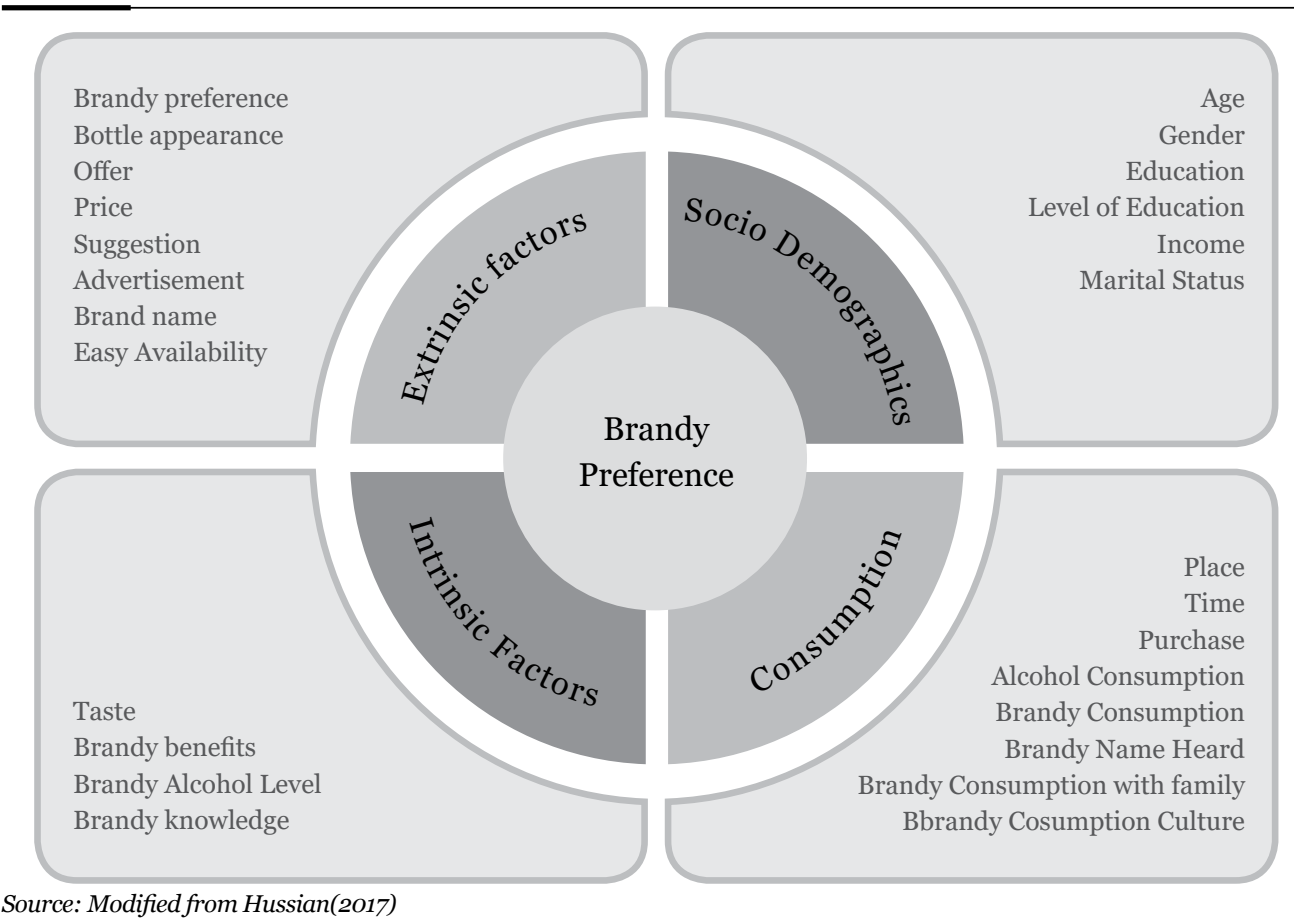

Source: Modified from Hussian(2017) 


\section{Discussion}

The alcohol beverage market is growing with the CAGR of $2 \%$ from 2018 to 2025 due to the higher demand from developing countries where gin is estimated to grow higher among the liquors followed by whisky, mixed drink, vodka, beer and wine. Salanta (2016) defined brandy as an alcoholic drink produced through the distillation and fermentation of fruits such as apples, plums and pears with the $40 \%$ alcohol concentration. Brandies are fermented products of the wine or fruits and can come from anywhere in the world as it refers to a distilled spirit made from fermented fruit juice. There is no hard and fast difference in brandies and other spirits in terms of packaging and managerial strategies but the only difference is the raw materials used. In the study of alcoholic type of beverage preference conducted by Ramasubranian et al. (2018), brandy was the most preferred beverage among alcohol abusers among 18-60 years age group. Consumers' preferences can vary from one person to another depending on factors like products intrinsic and extrinsic factors, consumers' perception towards the product and the external environment like the peer preference, retailers' suggestions and advertisements. The study made by Gunay and Baker (2011) revealed that the consumers' preferences are not only influenced by socio demographic, as well as consumer demographic characteristics, but also by extrinsic factors. In different scenarios, there can be the difference between the persons' willingness to pay for products and the actual amount paid for the product. During the study made on the stated willingness to pay for the sustainable wine and the actually paid amount, the amount paid was much lower than they desired to pay (Barber et al., 2012). The consumers' preference may differ even for the same product, due to which the organization must focus on developing the managerial activities and marketing strategies for the product promotion.

In 21st century, social media marketing has been the most influential marketing tool, with platforms like Facebook and YouTube to promote the products on. In the alcohol industry, Facebook is growing as the best tool for product promotions due to the presence of the individuals with different age, gender, preference, habits. However, the site cannot be used for establishing foreign relations due to lack of foreign language proficiency among the users. (Movsisyan, 2016; Lim et al., 2016). You Tube has also provided an excellent platform for marketers, who utilize tailored marketing approaches to cater specific national contexts and develop content on the cultural meanings that users invoke in their interactions. For premium alcoholic beverages like brandy and single malt whisky, promotion through personal sales and recommendations from experts and retailers have significant positive impacts (Chan, 2018).

The alcohol content in beverages depend on Ethanol i.e. a colorless volatile flammable liquid which is produced by natural fermentation of sugar and is measured with ABV. In the wide category of alcoholic beverages, whisky, rum, brandy and scotch are the popular categories. Public health is a matter of great concern for the government and thus they can implement tax for controlling alcohol consumption in the nation. The study made by Cook (1982) revealed that the increase in tax results on sharp reduction on liquor consumption. Though brandy is a premium product and reflects social status, changes in price have negative impact in demand. 
From the study made on socio demographic impact of the alcohol beverage consumption, we have come to find out that alcohol consumption and product selection is dependent on the age, occupation, gender, income and socio economic status, peer groups, family and advertisement (Casswell, 2003). Therefore alcohol product companies can position and advertise the products in terms of socio demographics and economic social status. Consumer preference is defined as the subjective tastes of individual consumers, measured by their satisfaction with those items after they've purchased them and are measured in terms of utility. The consumer preference theories explain that the person's behavior is the outcome of his/ her subjective norms and attitude but the attitude are influenced by various factors like values, personality, and culture of decision making. For measuring the preferences of consumers, the conjoint analysis can be used to measures the consumer preferences on the basis of the bundles of attributes rather than the individual attributes. The conceptual framework developed shows various factors that guide people for preference on any product. In this study, the consumer preference for brandy is intended to measure under the different headings like socio demographic, extrinsic features of the product, intrinsic features of the product and market information about the product. The socio demographic consists of the variables like age, income, sex, education and marital status. Whereas the extrinsic factors consist of variables like brand loyalty, brand awareness and bottle awareness, intrinsic factors consist of the variables like taste, price and alcohol content. Promotion consists of the variables like discount, offer and advertisement. Reference consists of the variables like family preferences, peer consumptions and retailer suggestions.

\section{Conclusion}

The study made on the literature review found that a large set of studies have been conducted on the preference of alcohol beverages, study on wine preferences and on the marketing strategies that could be effective on the promotion of beverages as well as on the remedies for controlling alcoholism. Alcohol industry is currently the fastest growing industry in the world, where wide product segmentation can be made on the basis of socio demographics, social class and economic factors. The industries require consumer preference for the promotions and penetration of the product into the market, and for developing the product and improving it further. This study explored the knowledge of brandy among people and the factors determining the selection of brandy among other alcohol beverages. This study is also

focused on providing the managerial solutions for alcohol beverage industries in promoting alcoholic beverages.

\section{Acknowledgement}

Earlier version of this paper has been presented at International Business Conference (IBC, 2019) in Mid-western University; Surkhet, Nepal dated 14th-15th July 2019.

\section{Conflict of Interest}

No conflict of interest existed while preparing this paper. 


\section{References}

Alcoholic beverages: Amount of alcohol in alcoholic beverages, (n.d.). Nutrients Review. Retrieved from http://www.nutrientsreview.com/alcohol/alcoholic-beverages-abv-calories.html

Barber, N., Kuo, P. J., Bishop, M., \& Goodman Jr, R. (2012). Measuring psychographics to assess purchase intention and willingness to pay. Journal of consumer marketing, 29(4), 280-292.

Bougas, N. V. (2014). Factors influencing the style of brandy (Doctoral dissertation). Stellenbosch University, South Africa.

Business wire. (2018). Global alcoholic beverage market analysis, growth, trends and forecasts 2018202. Dublin: Eastern Daylight Time. Retrieved from https://www.businesswire.com/news/ home/20180801005550/en/Global-Alcoholic-Beverage-Market-Analysis-Growth-Trends.

Casswell, S., Pledger, M., \& Hooper, R. (2003). Socioeconomic status and drinking patterns in young adults. Addiction, 98(5), 601-610.

Chan, D. (2018). How do consumers select wine? Factors that affect the purchasing decision of wineconsumers in Singapore. Perspectives in Asian Leisure and Tourism, 3(1), 1-11.

Cook, P. J., \&Tauchen, G. (1982). The effect of liquor taxes on heavy drinking. The Bell Journal of Economics, 379-390.

Davitt, D. (2019, May 29). Global alcohol consumption dips in 2018 with moderate growth forecast for next five years. UK: The ModdieDavitt Report. Retrieved from https://www.moodiedavittreport.com/global-alcohol-consumption-dips-in-2018-moderate-growth-forecast-for-nextfive-years-says-iwsr/

de Lorimier, A. A. (2000). Alcohol, wine, and health. The American Journal of Surgery, 180(5), 357-361.

Dey, M., Gmel, G., Studer, J., Dermota, P., \& Mohler-Kuo, M. (2013). Beverage preferences and associated drinking patterns, consequences and other substance use behaviours. The European Journal of Public Health, 24(3), 496-501.

Dubas, K. M., \& Strong, J. T. (1993). Course design using conjoint analysis. Journal of Marketing Education, 15(1), 31-36.

Duncan Kitchin, P. (1981). Some socio-economic determinants of alcohol consumption: a research note. International Journal of Social Economics, 8(5), 31-35.

Engel, J. F., Kollat David T., \& Blackwell, R. D. (1968). Consumer behavior. Holt, Rinehart and Winston

Food \& Beverage.(n.d.).Set up my hotel. Retrieved from https://setupmyhotel.com/train-my-hotelstaff/f-and-b/371-alcoholic-beverages.html

Guris, S., Metin, N., \& Caglayan, E. (2007). The brand choice model of wine consumers: a multinomial logit model. Quality \& Quantity, 41(3), 447-460.

Harrison, J.B. (1971). Community Treatment of Alcoholics. Alcohol and Alcoholism. 130(1), 36-47.

Hussain, M. (2017). Study on consumer decision making process in the selection of home cleaning company: Case company: MHB Clean Helsinki.International Business. 4(2), 1-38.

Jaafar, S. N., Lalp, P. E., \& Naba, M. M. (2012). Consumers' perceptions, attitudes and purchase intention towards private label food products in Malaysia. Asian Journal of Business and Management Sciences, 2(8), 73-90.

Jacki, (2019, March 6). 9 types of brandy all you need to know. Retrieved from https://blog.cognac-expert.com/9-types-of-brandy-all-you-need-to-know/

Khorshiddoust, A. M. (2013). Hedonic Prices and Environmental Classification of Economic Values of Selected Areas of Tabriz. International Journal of Economics and Finance Studies, 5(2), 108-121.

Kim, J., Rasouli, S., \&Timmermans, H. (2014). Hybrid choice models: principles and recent progress incorporating social influence and nonlinear utility functions. Procedia Environmental Sciences, 22, 20-34. 
Lim, M. S., Hare, J. D., Carrotte, E. R., \&Dietze, P. M. (2016). An investigation of strategies used in alcohol brand marketing and alcohol-related health promotion on Facebook. Digital Health, 2, 2055207616647305.

Louw, L. (2014). Sensory analysis of brandy: the application of rapid profiling methodologies (Doctoral dissertation). Stellenbosch University, South Africa.

Mandara, S. (2018, March 12). Different types of alcohol. Retrieved from https://tastessence.com/ different-types-of-alcohol.

Mehta, R., \& Bhanja, N. (2018). Consumer preferences for wine attributes in an emerging market. International Journal of Retail \& Distribution Management, 46(1), 34-48.

Mkosi, Chiliya, \& Chikandiwa. (2016). Leisure time and alcohol beverage preferences of young people in South Africa: A structural model analysis. African Journal of Hospitality, Tourism and leisure, $5(3), 1-20$.

Movsisyan, S. A. (2016). Social media marketing strategy of Yerevan brandy company. Annals of Agrarian Science, 14(3), 243-248.

Nayak, N. P., \& Prabhu, N. B. (2013). A study on alcohol consumption patterns and preference of liquor over wine amongst the youth in Manipal. Journal of Hospitality and Tourism (Atithi), 1(1), 77-88.

NazanGunay, G., \& Baker, M. J. (2011). The factors influencing consumers' behaviour on wine consumption in the Turkish wine market. Euromed Journal of Business, 6(3), 324-341.

Niland, P., McCreanor, T., Lyons, A. C., \& Griffin, C. (2017). Alcohol marketing on social media: young adults engage with alcohol marketing on facebook. Addiction Research \& Theory, 25(4), 273-284.

Paasovaara, R., Luomala, H. T., Pohjanheimo, T., \&Sandell, M. (2012).Understanding consumers' brand-induced food taste perception: A comparison of 'brand familiarity'-and 'consumer value-brand symbolism (in) congruity'-accounts. Journal of Consumer Behaviour, 11(1), 11-20.

Paudel, U. R., \&Devkota, N. (2018). Socio-Economic influences on small business performance in Nepal-India open border: Evidence from cross-sectional analysis. Economics \& Sociology, 11(4), 11-30.

Paudel, U. R., Devkota, N., \& Bhandari, U. (2018). Socio-cultural and economic factors in cross-border purchase: A study of customers' perspective in Sunauli-Nepal/India Border. Modern Economy, 9(6), 1089-1102.

Pentz, C., \& Gerber, C. (2013). The influence of selected senses on consumer experience: A brandy case. ActaCommercii, 13(1), 1-7.

Pettigrew, S., \& Charters, S. (2010). Alcohol consumption motivations and behaviours in Hong Kong. Asia Pacific Journal of Marketing and Logistics, 22(2), 210-221.

Prasanna, A. (2018, Sep). Alcoholic beverage market overview. Canada: Allied Market Research. Retrieved from https://www.alliedmarketresearch.com/alcoholic-beverages-market

Ramasubramanian, V., Chellamuthu, R., Pandian, P. R. S., Mathumathi, S., Selvikumari, R., \& Gopi, R. (2018). Alcoholic beverage preference and in person with alcohol dependence: southern Tamil Nadu. International Journal Of Community Medicine And Public Health, 5(4), 1634-1638.

Rathod, S. D., Luitel, N. P., \& Jordans, M. J. D. (2018). Prevalence and correlates of alcohol use in a central Nepal district: secondary analysis of a population-based cross-sectional study. Global Mental Health, 5 .

Salanță, L. C., Tofană, M., Mudura, E., Pop, C., Pop, A., \& Coldea, T. (2016). The alcoholic beverage consumption preference of university students: A preliminary Romanian case study. Bulletin of University of Agricultural Sciences and Veterinary Medicine Cluj-Napoca. Food Science and Technology, 73(1), 33-39.

Sancho, F. M., Miquel, M. J., \& Aldás, J. (2011). Factors influencing youth alcohol consumption intention. An approach from consumer socialization theory. Journal of Social Marketing, 1(3), 192-210.

Sawagvudcharee, O., Shrestha, S., \& Mandal, S. (2018). Impacts of brand on consumer decision mak- 
ing: A case study of beer brands in Nepal.

Stanz, C. (2018, Sep 26). 7 reasons to enjoy an after-dinner snifter of brandy.Wide Opean Eats. Retrieved from https://www.wideopeneats.com/health-benefits-of-brandy/

Stearns, B. (2018). What is brandy and what makes it special. Retrieved from https://spoonuniversity.com/lifestyle/what-is-brandy-and-what-makes-it-special

Wiki. (n.d.). How to drink brandy. Retrieved from https://www.wikihow.com/Drink-Brandy\#Learning_About_and_Choosing_Your_Brandy_sub

World health organization. (2018). Management of substance abuse: Global status report on alcohol and health, 2018. World Health Organization, 1-472. Retrieved from https://www.who.int/substance_abuse/publications/global_alcohol_report/en/ 